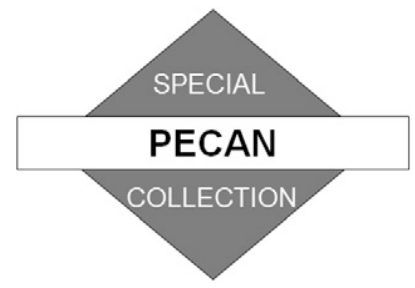

\title{
Impacts of Modifications to a Local Planetary Boundary Layer Scheme on Forecasts of the Great Plains Low-Level Jet Environment
}

\author{
DAVid E. JAHN AND WiLliam A. GALlus JR. \\ Department of Geological and Atmospheric Sciences, Iowa State University, Ames, Iowa
}

(Manuscript received 28 February 2018, in final form 13 July 2018)

\begin{abstract}
The Great Plains low-level jet (LLJ) is influential in the initiation and evolution of nocturnal convection through the northward advection of heat and moisture, as well as convergence in the region of the LLJ nose. However, accurate numerical model forecasts of LLJs remain a challenge, related to the performance of the planetary boundary layer (PBL) scheme in the stable boundary layer. Evaluated here using a series of LLJ cases from the Plains Elevated Convection at Night (PECAN) program are modifications to a commonly used local PBL scheme, Mellor-Yamada-Nakanishi-Niino (MYNN), available in the Weather Research and Forecasting (WRF) Model. WRF forecast mean absolute error (MAE) and bias are calculated relative to PECAN rawinsonde observations. The first MYNN modification invokes a new set of constants for the scheme closure equations that, in the vicinity of the LLJ, decreases forecast MAEs of wind speed, potential temperature, and specific humidity more than 19\%. For comparison, the Yonsei University (YSU) scheme results in wind speed MAEs $22 \%$ lower but specific humidity MAEs $17 \%$ greater than in the original MYNN scheme. The second MYNN modification, which incorporates the effects of potential kinetic energy and uses a nonzero mixing length in stable conditions as dependent on bulk shear, reduces wind speed MAEs $66 \%$ for levels below the LLJ, but increases MAEs at higher levels. Finally, Rapid Refresh analyses, which are often used for forecast verification, are evaluated here and found to exhibit a relatively large average wind speed bias of $3 \mathrm{~m} \mathrm{~s}^{-1}$ in the region below the LLJ, but with relatively small potential temperature and specific humidity biases.
\end{abstract}

\section{Introduction}

The influence of the Great Plains low-level jet (LLJ) on the initiation and evolution of nocturnal convection in the central United States, through its northward transport of heat and moisture and an increase in low-level convergence, has been investigated by several studies as reviewed in Stensrud (1996). Climatologically, linkages between the LLJ and a maximum in moisture transport and associated precipitation in spring and summer over the Great Plains have been identified (Higgins et al. 1997; Walters and Winkler 2001). Stronger moisture convergence and convection exist for specific events if the LLJ is coupled with upper-level features that promote vertical motion, such as a baroclinic wave or a lower-tropospheric front (Augustine and Caracena 1994; Wang and Chen 2009). Squitieri and Gallus (2016) find a higher predictive skill for rainfall from mesoscale convective systems

\footnotetext{
Corresponding author: David E. Jahn, djahn@iastate.edu
}

(MCSs) when the LLJ exists in a synoptic setting of cyclonic flow instead of one with anticyclonic flow. Forecasting LLJ location and strength is thus important for forecasting convective precipitation in the Great Plains.

Challenges remain, however, in the use of mesoscale models for LLJ forecasting. LLJ evolution is influenced by the turbulent mixing of the boundary layer $(\mathrm{Hu}$ et al. 2013; Klein et al. 2016), the parameterizations and effects of which differ among planetary boundary layer (PBL) schemes. Local PBL schemes, such as the Mellor-YamadaNakanishi-Niino (MYNN) PBL scheme (Mellor and Yamada 1982; Nakanishi 2001; Nakanishi and Niino 2004), parameterize the vertical eddy transport of heat and momentum using only gradients of mean variables that are defined locally. Nonlocal schemes, such as the Yonsei University (YSU) scheme (Hong et al. 2006), include a countergradient term in the boundary layer to account also for mixing effects of large eddies. The effect is a reduction in vertical gradients of heat and momentum and effective reduction in local mixing. In general, nonlocal 
PBL schemes result in relatively stronger wind speeds and warmer temperatures at low levels of the boundary layer over night as compared to local schemes (Kleczek et al. 2014; Hu et al. 2010).

For nonlocal schemes, vertical mixing is related to a diagnosed mixing length that represents the effective depth over which turbulent-eddy mixing has relevant influence on boundary layer evolution. According to similarity theory, turbulence would start to diminish as the gradient Richardson number ( $\mathrm{Ri}$ ) exceeds 0.25 and tend toward zero as the boundary layer stability becomes relatively large, such as when Ri approaches 1.0 (Grachev et al. 2013). Mixing length in PBL schemes is thus often dependent on stability either defined by a Richardson number or Obukhov length (Schmengler et al. 2015; Milovac et al. 2016). The MYNN scheme defines mixing length in consideration of environmental stability, the vertical profile of turbulent kinetic energy (TKE), and buoyancy effects (Nakanishi 2001).

Certain studies have countered the conventional thinking of similarity theory, giving evidence that significant turbulence persists even under relatively strong stable conditions as related either to nonzero turbulence potential energy (Zilitinkevich et al. 2007, hereafter ZL07) or an increase in mixing length in a stable environment for conditions of relatively strong bulk wind shear (Sun et al. 2012).

In the MYNN scheme, forecasted vertical mixing and boundary layer evolution are sensitive also to the closure parameters, which are constants that determine the relative influence of shear or buoyancy terms of the second-order closure equations in the production of turbulent energy or of terms related to energy dissipation or redistribution (Nakanishi 2001; Jahn et al. 2017b). Based on large-eddy simulation (LES) data of simulated LLJ cases, Jahn et al. (2017a, hereafter J17a) derive a new set of MYNN closure parameters to improve LLJ mesoscale model wind speed forecasts.

The unique contribution of the present study is the evaluation of recent modifications to the MYNN PBL scheme in the forecast of the Great Plains LLJ. As described above, these modifications include a new set of closure parameters, the inclusion of turbulent potential energy, and an updated mixing length formulation for the stable boundary layer (SBL) related to bulk shear.

Unique also to this study is the use of nighttime observations for forecast validation that are of spatial and temporal resolution considerably higher than conventionally available. The Plains Elevated Convection at Night (PECAN) program (Geerts et al. 2017) provides a plethora of in situ and remotely sensed observations during active weather days over the central Great Plains during 1 June-15 July 2015. The PECAN data allow for verification of model forecasts directly against observations rather than strictly against model reanalyses, as is often done. Accordingly, this study also investigates the veracity of using model analyses as reference "truth" to validate LLJ forecasts in a manner similar to what Thompson et al. (2003) did for severe storm environments.

In the present study, specific forecasts of environmental parameters that characterize the LLJ environment and its influence on convective storm development, including wind speed, potential temperature, specific humidity, and thermodynamic stability, are evaluated using a model run with convection-allowing horizontal grid spacing and with variations in the PBL scheme. To allow for comparison with a nonlocal PBL scheme, LLJ forecasts using the YSU scheme are also considered. PBL scheme modifications are described in section 2. The setup of model experiments based on select PECAN LLJ cases is described in section 3. Section 4 presents general results of model forecasts based on different PBL schemes as well as an evaluation of the appropriateness of using model analyses for validation. Section 5 summarizes the results and discusses future work.

\section{Modifications to PBL schemehereafter}

The various PBL scheme modifications as evaluated here are described below. All are implemented within the framework of the MYNN PBL scheme in the Weather Research and Forecasting (WRF; Skamarock et al. 2008) Model version 3.8.

\section{a. New closure parameters for the $S B L$}

To define the mixing effects of turbulent eddy covariance in a mesoscale model, the MYNN PBL scheme uses a set of closure equations, in which a set of parameters determine the relative influence of turbulent energy production, dissipation, and redistribution. Example equations used to calculate 2 of the 10 momentum, heat flux, and variance terms $\left(\overline{u_{i} u_{j}}\right.$ and $\overline{u_{i} \theta}$ using Einstein notation, as well as $\left.\overline{\theta^{2}}\right)$ are

$$
\begin{aligned}
& \overline{u w}=\frac{3 A_{1} L}{q}\left[\left(C_{1} q^{2}-\overline{w^{2}}\right) \frac{\partial U}{\partial z}+\alpha g\left(\overline{w \theta}-C_{2} \overline{u \theta}\right)\right] \\
& \overline{w \theta}=\frac{3 A_{1} L}{q}\left[\overline{w^{2}} \frac{\partial \Theta}{\partial z}+\left(1-C_{3} \frac{g}{\theta_{0}} \overline{\theta^{2}}\right)\right]
\end{aligned}
$$

where $A_{1}, C_{2}$, and $C_{3}$ are 3 of the 8 MYNN closure parameters. (Reference J17a for the full list of covariance equations.) Variables $u$ and $v$ represent orthogonal horizontal components of the wind speed that are departures from the mean wind $U$ and $V$, while $w$ is the vertical wind. Here, $q$ is related to TKE such that $q^{2}=\overline{u^{2}}+\overline{v^{2}}+\overline{w^{2}}$. The mean potential temperature is $\theta$, and $\overline{\theta^{2}}$ is the potential temperature variance. The horizontal 
mean is represented by an overbar. Also, $L$ is the turbulent mixing length (the calculation of which is described below), $g$ is the vertical acceleration due to gravity, and $\alpha$ is a coefficient of thermal expansion.

$\mathrm{J} 17$ a formulate a new set of closure constants appropriate for use in the SBL (Table 1) using a set of inverted closure equations that define closure parameters, and which are dependent on eddy covariance values that are explicitly defined using LES data for a set of LLJ cases. Example equations for parameters $A_{1}$ and $B_{1}$ are given below and use the same variable nomenclature as in the above equations:

$$
\begin{aligned}
& A_{1}=\frac{-\frac{q}{3 L} \overline{u v}}{\overline{u w} \frac{\partial V}{\partial z}+\overline{v w} \frac{\partial U}{\partial z}} \quad \text { and } \\
& B_{1}=\frac{\frac{q^{3}}{L}}{\overline{u w} \frac{\partial U}{\partial z}+\overline{v w} \frac{\partial V}{\partial z}-g \alpha \overline{w \theta}} .
\end{aligned}
$$

Details of this modification are given in J17a.

\section{b. New mixing length}

The current MYNN scheme diagnoses the turbulent mixing length using

$$
\frac{1}{L}=\frac{1}{L_{S}}+\frac{1}{L_{T}}+\frac{1}{L_{B}}
$$

such that $L_{S}$ is related to Obukhov length, $L_{T}$ incorporates the influence of TKE, and $L_{B}$ considers buoyancy effects (see Nakanishi 2001 for details). This approach, in accordance with Monin-Obukhov theory, limits vertical mixing within the context of an SBL. Recent studies, however, have documented an increase in turbulence intensity in an SBL, and thus also mixing length, with an increase in wind speed when velocities are above a certain threshold (Sun et al. 2012). Based on these findings, a new expression for mixing length has been formulated by J17a and implemented here:

$$
L=0.75 \frac{z_{\mathrm{BL}}\left[V(z)-V_{s}\right]}{V_{\text {rel }}} .
$$

This expression is applicable for an SBL when the mean wind speed at a given level $V(z)$ is above a set threshold, $V_{s}=8 \mathrm{~m} \mathrm{~s}^{-1}$. The diagnosed boundary layer depth is $z_{\mathrm{BL}}$, and $V_{\text {rel }}$ is arbitrarily set to $10 \mathrm{~m} \mathrm{~s}^{-1}$. The maximum value of $L$ is restricted to the boundary layer depth $z_{\mathrm{BL}}$.

As stated in J17a, Eq. (6) is rudimentary in its application of the results found in Sun et al. (2012) related to the mixing length. Even so, this approach, which allows for a larger mixing length as compared to similarity
TABLE 1 . The original and new MYNN closure parameters.

\begin{tabular}{lcccccccc}
\hline \hline $\begin{array}{c}\text { Closure } \\
\text { parameter }\end{array}$ & $A_{1}$ & $A_{2}$ & $B_{1}$ & $B_{2}$ & $C_{1}$ & $C_{2}$ & $C_{3}$ & $C_{5}$ \\
\hline Original & 1.18 & 0.67 & 24.0 & 15.0 & 0.14 & 0.73 & 0.34 & 0.20 \\
New & 0.38 & 0.61 & 15.0 & 11.4 & 0.03 & 0.73 & 0.79 & 0.20 \\
\hline
\end{tabular}

theory, provided a level of improvement in model depiction of PBL evolution for certain LLJ experiments in $\mathrm{J} 17 \mathrm{a}$ and thus is considered once again here within the context of Great Plains LLJ cases.

\section{c. Explicit inclusion of turbulent potential energy}

ZL07 propose the explicit inclusion of turbulent potential energy (TPE) in the PBL scheme turbulence closure equations using

$$
E_{P}=\frac{1}{2}\left(\frac{\beta}{N}\right)^{2} \overline{\theta^{2}},
$$

for which $N$ is the Brunt-Väisälä frequency, $\overline{\theta^{2}}$ is the potential temperature variance, and $\beta=g / T_{0}$ is a buoyancy parameter with $T_{0}$ a reference absolute temperature. ZL07 derive an expression for vertical motion fluctuations $E_{z}$ that are dependent on TPE through a flux Richardson number, $\mathrm{Ri}_{f}=E_{P} /\left(E_{K}+E_{P}\right)$ (where $E_{K}$ is TKE), along with mean wind shear such that

$$
\begin{aligned}
E_{z}= & \left\{2 S_{z} \psi_{\tau} L^{2}\left[\left(\frac{\partial U}{\partial z}\right)^{2}+\left(\frac{\partial V}{\partial z}\right)^{2}\right]\right. \\
& \left.\times\left[1-\operatorname{Ri}_{f}\left(\frac{3}{C_{r} \psi_{3}}+1\right)\right]\right\} .
\end{aligned}
$$

Here,

$$
\begin{aligned}
& \psi_{\tau}=C_{\tau 1}+C_{\tau 2} \mathrm{Ri}_{f}, \\
& \psi_{3}=1+C_{3} \mathrm{Ri}_{f}, \quad \text { and } \\
& S_{z}=\frac{C_{K} C_{r} \psi_{3}}{3\left(1+C_{r}\right)},
\end{aligned}
$$

where the constants $C_{r}=3, C_{K}=1.08, C_{\tau 1}=0.228$, $C_{\tau 2}=-0.208$, and $C_{3}=-2.25$ are derived empirically in ZL07.

Rather than assuming system dependence on a threshold Richardson number, above which stability would dictate suppression of turbulence and associated vertical motion (as is the case of Monin-Obukhov theory), $E_{z}$ sustains turbulence associated with the mean shear even under strongly stable conditions. Finally, to calculate the eddy covariance, eddy viscosity is determined using

$$
K_{M}=2 \psi_{\tau} E_{z}^{0.5} L
$$


TABLE 2. Description of PBL parameterization schemes evaluated. Individual schemes are described in section 2.

\begin{tabular}{|c|c|}
\hline Label & PBL scheme \\
\hline MYNNorig & $\begin{array}{l}\text { Original MYNN scheme, version } 3.0(\mathrm{v} 3.0) \text {, per } \\
\text { WRF v3.8 }\end{array}$ \\
\hline MYNNnew & $\begin{array}{l}\text { MYNN scheme, v3.0, with new closure } \\
\text { parameters (J17a) }\end{array}$ \\
\hline ZLSun & $\begin{array}{l}\text { Explicit inclusion of TPE (ZL07) invoked within } \\
\text { the framework of the MYNN scheme with a new } \\
\text { mixing length for the SBL in consideration of } \\
\text { bulk shear (Sun et al. 2012, J17a) }\end{array}$ \\
\hline YSU & YSU scheme per WRF v3.8 \\
\hline
\end{tabular}

\section{Methodology}

Four experiment types are configured based on model forecasts with varying combinations of PBL scheme modifications (Table 2) as described in section 2 and are referred to as MYNNorig, MYNNnew, ZLSun, and YSU. The first three are based on the MYNN scheme framework. YSU is used to provide a comparison with a commonly used nonlocal scheme.

PBL scheme modifications are evaluated based on WRF Model forecasts of $12 \mathrm{LLJ}$ cases from the PECAN project and compared against rawinsonde observations at fixed sites in the PECAN domain (Fig. 1 and Table 3). The 12 cases are chosen with a nocturnal LLJ over the PECAN region (primarily over Kansas) with core wind speeds greater than $10 \mathrm{~m} \mathrm{~s}^{-1}$ lasting for several hours. Several wind speed thresholds have been considered here, and using $10 \mathrm{~m} \mathrm{~s}^{-1}$ differentiates well the LLJ region. Also, to avoid the direct effects of nearby convection, we select cases with no precipitation at or near a majority of PECAN fixed rawinsonde sites during balloon launch periods (generally 0000-0600 UTC). The dates in 2015 of chosen cases include $3,11,20,22,24,25$, and 26 June and 1, 6, 10,12 , and 16 July. The LLJ occurred for each case between 0000 and 1200 UTC.

The model configuration is identical for all forecasts of any one LLJ case. The $1000-\mathrm{km}^{2}$ horizontal domain with 4-km grid spacing is centered over Kansas City, Missouri (Fig. 1). Vertically, the domain extends to $100 \mathrm{hPa}$ and uses a stretched grid of 46 sigma levels with 10 points below $250 \mathrm{~m}$ AGL to resolve well the LLJ. (Tests with double the number of vertical grids in the LLJ region yielded similar results.) Model initial and boundary conditions are provided by the North American Mesoscale Forecast System (NAM) archived files through the National Centers for Environmental Information. WRF boundary conditions are based on NAM forecasts that are initialized at the same time as the WRF forecasts. The NAM data are at $12-\mathrm{km}$ grid spacing,

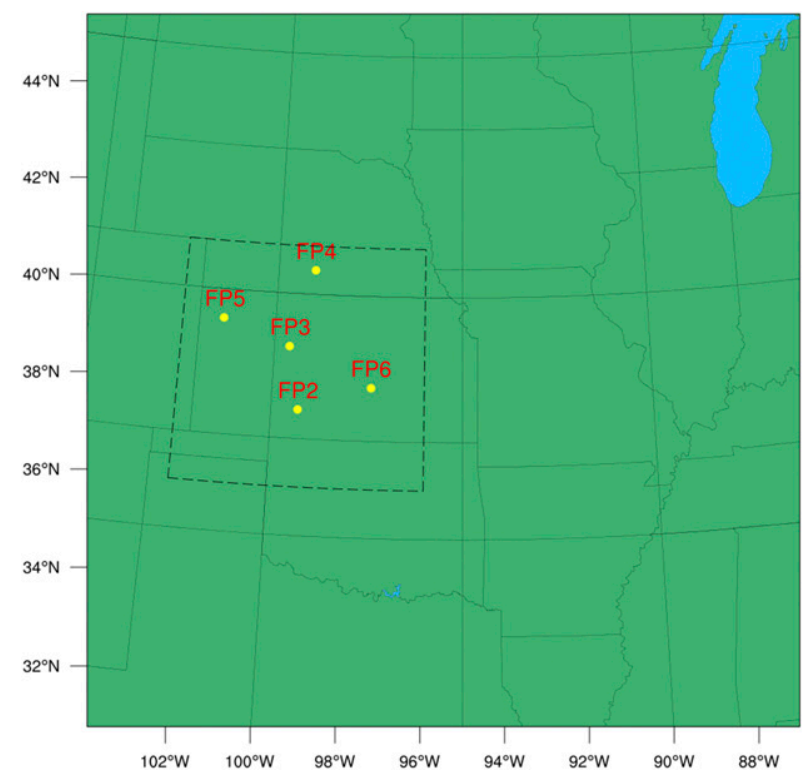

FIG. 1. WRF domain (green area) showing the region of the PECAN study (box with dashed line) and the launch sites of PECAN rawinsondes used for WRF forecast validation (Table 3).

which provides an even 3:1 grid ratio for downscaling to the WRF grid at 4-km grid spacing. The 24-h WRF forecasts are initialized at 1200 UTC, and boundary conditions are updated every $6 \mathrm{~h}$. All forecasts use the Noah land surface scheme (Chen and Dudhia 2001) and the WRF single-moment 5-class (WSM5) microphysical scheme (Hong et al. 2004). Shortwave and longwave radiation processes are represented, respectively, by the Dudhia scheme (Dudhia 1989) and the Rapid Radiative Transfer Model (RRTM; Mlawer et al. 1997). No cumulus parameterization scheme is used.

WRF forecasts are evaluated by calculating mean absolute error (MAE) and bias for wind speed, potential temperature, and specific humidity relative to five PECAN rawinsonde soundings (Holdridge and Turner 2015; Vermeesch 2015; Clark 2016; UCAR-NCAR 2016a,b) available in the model domain and within the WRF forecast period. PECAN data for potential temperature and specific humidity are derived using temperature and relative humidity observations. The WRF data are extracted as a vertical 1D profile at the grid point nearest to the location of a given PECAN sounding (five sites). PECAN sounding data are log interpolated to sigma levels of the WRF vertical grid. (Data are interpolated to sigma levels rather than pressure levels to alleviate interpolation errors when there are discrepancies between surface pressures of the WRF and the observations.) MAEs and bias are averaged over three specified vertical 
TABLE 3. PECAN launch sites for rawinsonde data used in the study.

\begin{tabular}{clrcc}
\hline \hline Site ID & \multicolumn{1}{c}{ Location } & Lon $\left(^{\circ}\right)$ & Lat $\left(^{\circ}\right)$ & Elev $(\mathrm{m})$ \\
\hline FP2 & Greensburg, KS & -99.3 & 37.6 & 681 \\
FP3 & Ellis, KS & -99.6 & 38.9 & 646 \\
FP4 & Minden, NE & -99.0 & 40.5 & 662 \\
FP5 & Brewster, KS & -101.4 & 39.4 & 1045 \\
FP6 & Hesston, KS & -97.4 & 38.1 & 451 \\
\hline
\end{tabular}

layers: the surface layer (from the surface up to $150 \mathrm{~m}$ AGL, which is generally the region below the core of the LLJ), the LLJ layer (between 150 and $700 \mathrm{~m}$ AGL, the layer that generally coincides with the core of the LLJ), and the layer above the LLJ (above 700 and below $2500 \mathrm{~m}$ AGL). Because this grid is nonuniform and stretched, the vertical averages of the MAE and bias values are weighted at a given point by the vertical grid spacing at that point. These error values are then averaged across all times for which PECAN data are available (generally 0000-0600 UTC), across the five PECAN rawinsonde sites in the WRF domain, and across the 12 cases to obtain a single MAE or bias value for each PBL scheme and for each of the three defined vertical regimes (above, below, and concurrent with the LLJ).

A $t$ test is used to determine if the difference in the average MAEs associated with two PBL schemes is statistically significant. Specifically, a paired-sample $t$ test is used, which evaluates the null hypothesis that two related datasets have identical means (here average MAEs). A single data point in these MAE datasets represents the vertically averaged difference between a WRF forecast based on one of four PBL schemes, and rawinsonde sounding data from one of five PECAN sites, for 1 of the 12 LLJ cases, and at one specific time (generally between 0000 and 0600 UTC). Each dataset is a collection of individual MAE data points that are gathered from forecasts using the same PBL scheme (MYNNorig, MYNNnew, ZLSun, and YSU) and the same vertical layer (below, above, and concurrent with the LLJ). This yields datasets of sufficiently large sample size (generally over $275 \mathrm{MAE}$ data points) for a $t$ test to determine statistical differences (Ghasemi and Zahediasl 2012). A $P$ value of less than 0.05 is used to indicate that the difference in average MAEs between the PBL schemes is statistically significant.

The veracity of using model analysis data for validation purposes is evaluated by comparing Rapid Refresh (RAP) analyses (Benjamin et al. 2016) with PECAN rawinsonde observations. The National Centers for Environmental Prediction of the National Oceanic and Atmospheric Administration (NOAA) produce a RAP analysis every hour based on a 3D assimilation of available data from the various NOAA observation platforms (surface, radar, rawinsonde, satellite, etc.), which are extensive, but not ubiquitous. RAP analysis MAE and bias are calculated using the same method as in the evaluation of WRF forecasts based on extracted vertical profiles of PECAN data for the five PECAN sites and 12 LLJ cases interpolated to WRF sigma levels as compared with associated PECAN rawinsonde profiles of wind speed observations and derived values of potential temperature and specific humidity. It should be noted that PECAN data are not assimilated as part of the RAP analyses.

\section{Results}

MAE and bias are computed relative to PECAN rawinsonde observations across all forecasts associated with the same PBL scheme (MYNNorig, MYNNnew, ZLSun, and YSU) to ascertain the impact on WRF Model forecast skill for wind speed, potential temperature, and specific humidity as well as CAPE and CIN for a set of LLJ cases. The MAEs and bias of RAP analyses are evaluated as well for the same LLJ cases. The $t$-test results are not explicitly presented here, and differences between MAE values among forecasts of different PBL schemes are interpreted as being statistically significant unless noted otherwise.

\section{a. Wind speed forecasts}

Composite plots of WRF forecast and RAP analysis wind speed values and bias relative to PECAN observations are given (see Figs. 2 and 4 ) and comprise data as averaged across all 60 experiments. Because the suite of experiments represents five sites in the PECAN domain at varying elevation levels, the composites are formulated using wind speeds at reference heights that are locally defined above ground level. A composite timeline of average wind speed bias at $525 \mathrm{~m}$ AGL (a height that is generally in proximity to the observed LLJ peak) shows MYNNnew wind speed biases are $1 \mathrm{~m} \mathrm{~s}^{-1}$ or less at the general time of LLJ initiation, roughly around 0000 UTC for all cases, through 0300 UTC. Thereafter, MYNNnew winds at 525-m height are underpredicted by as much as $2 \mathrm{~ms}^{-1}$. The MYNNnew average peak magnitude of the LLJ at 0600 UTC is close to observed, but is displaced more than $300 \mathrm{~m}$ too low (Fig. 4), causing wind speeds to be underpredicted by as much as $2 \mathrm{~m} \mathrm{~s}^{-1}$ at the level of the observed LLJ peak $(525 \mathrm{~m}$; Fig. 3) and overpredicted at lower levels (Fig. 2). Even so, the MYNNnew bias is not as large as that of ZLSun or MYNNorig, which exhibit underforecast wind speeds of $3 \mathrm{~m} \mathrm{~s}^{-1}$ or more in the LLJ layer. A relatively low LLJ can be indicative of a relatively shallow PBL, which is a feature of local PBL schemes, such as MYNN, that has been observed by other studies 

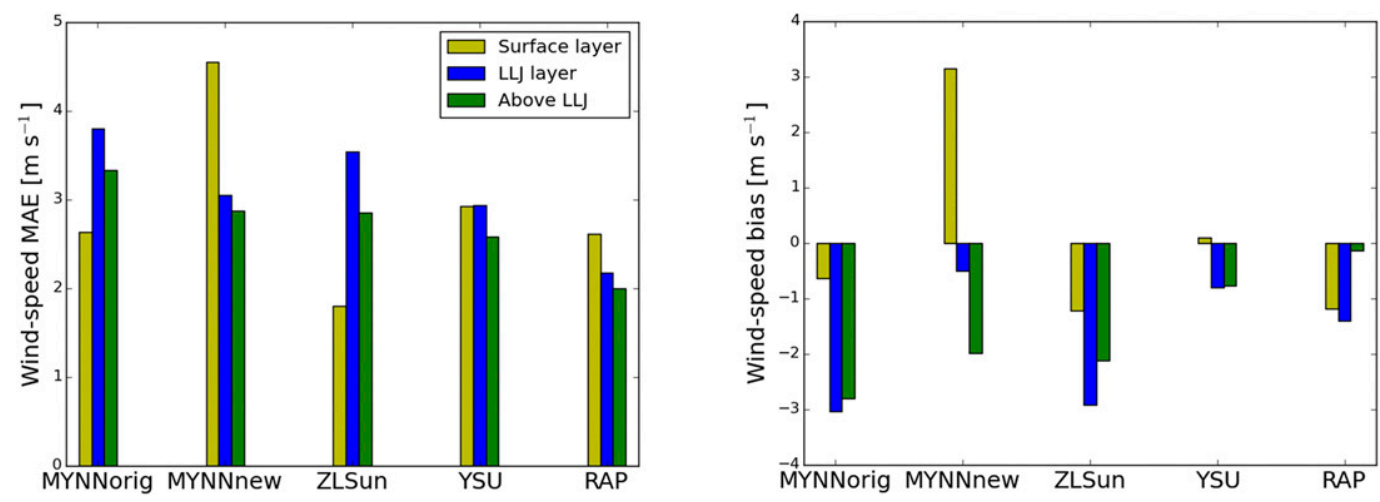

FIG. 2. WRF wind speed forecast by PBL scheme and RAP analysis (left) MAE ( $\mathrm{m} \mathrm{s}^{-1}$ ) and (right) bias $\left(\mathrm{m} \mathrm{s}^{-1}\right)$ for three vertical layers as defined in the text and designated by color as given in the legend. As described in the text, $\mathrm{MAE}$ and bias represent the average error across $12 \mathrm{LLJ}$ cases and five PECAN sites (60 experiments).

(Cohen et al. 2015; Cohen et al. 2017) and could be due to a local scheme's inability to represent well the effects of large-scale turbulent eddies.

The YSU composite also places the LLJ peak too low, about $150 \mathrm{~m}$ below that observed and, in addition, underpredicts the magnitude of the LLJ at 0600 UTC by $1.5 \mathrm{~m} \mathrm{~s}^{-1}$. Although YSU MAE, which is averaged over a 6-h period (0000-0600 UTC; Fig. 2), is $3 \mathrm{~m} \mathrm{~s}^{-1}$ over the LLJ layer, the composite of YSU wind speed bias at 0600 UTC is not more than $1.5 \mathrm{~m} \mathrm{~s}^{-1}$ and is the smallest at all levels as compared to the other PBL schemes. It is possible that the mixing of large-scale eddies, such as when using a local PBL scheme, allows for the entrainment of lower-momentum air above the LLJ and thus an effective reduction of the LLJ magnitude.

The RAP analysis composite timeline shows wind speeds at $525 \mathrm{~m}$ that are $1 \mathrm{~m} \mathrm{~s}^{-1}$ weaker than the observations during the development of the LLJ (0200-0400 UTC) and greater than the observed winds by $1 \mathrm{~m} \mathrm{~s}^{-1}$ at 0600 UTC after LLJ full development for levels above the wind maximum $(525 \mathrm{~m})$. Figure 2 shows the RAP analysis MAE over the LLJ layer is $2.1 \mathrm{~m} \mathrm{~s}^{-1}$ and its bias of $-1.2 \mathrm{~m} \mathrm{~s}^{-1}$ is larger in magnitude than the biases for MYNNnew and YSU. The surface layer presents a different picture, however, than the LLJ layer. Although the RAP bias is relatively small at higher levels, it increases up to $3 \mathrm{~m} \mathrm{~s}^{-1}$ just above the surface (Fig. 4). This result suggests potential problems for LLJ studies that invoke RAP analyses for forecast verification below $200 \mathrm{~m}$ AGL.

Although MYNNnew results in a lower average MAE for the LLJ layer as compared to MYNNorig, its average MAE for the surface layer is $1.9 \mathrm{~m} \mathrm{~s}^{-1}(72 \%)$ higher (Fig. 2). This forecast error consists of wind speeds that are largely overforecast, as indicated by a relatively large positive bias of $3.2 \mathrm{~m} \mathrm{~s}^{-1}$ for the surface layer. At
0600 UTC, the MYNNnew composite bias is greater than $6 \mathrm{~m} \mathrm{~s}^{-1}$ near the surface (Fig. 4). As mentioned above, these large wind speeds at lower levels are associated with an LLJ maximum that develops on average $300 \mathrm{~m}$ lower than observed. Conversely, ZLSun exhibits an average MAE that is much smaller for the surface layer as compared to the LLJ layer, with a value $0.8 \mathrm{~m} \mathrm{~s}^{-1}(31 \%)$ less than that of MYNNorig. Specifically at 0600 UTC (Fig. 4), the wind speed biases for MYNNorig and ZLSun are similar.

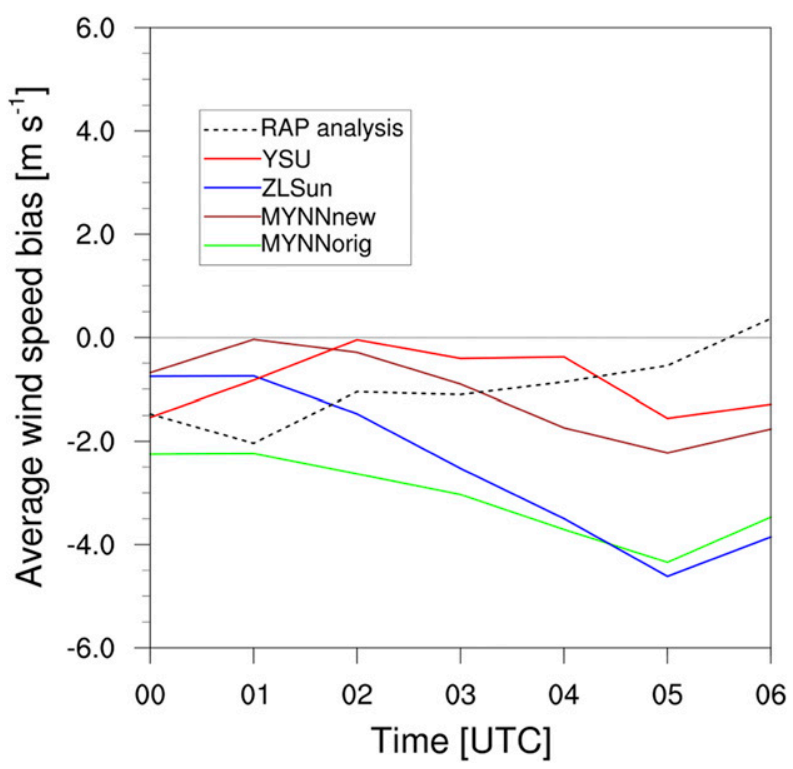

FIG. 3. For the same 60 experiments in Fig. 2, time series are given of WRF forecast composite and RAP analysis wind speed bias $\left(\mathrm{m} \mathrm{s}^{-1}\right)$ relative to PECAN rawinsonde observations at $525 \mathrm{~m}$ AGL between 0000 and 0600 UTC. WRF forecasts using different PBL schemes and RAP analyses are designated by color as given in the legend. 

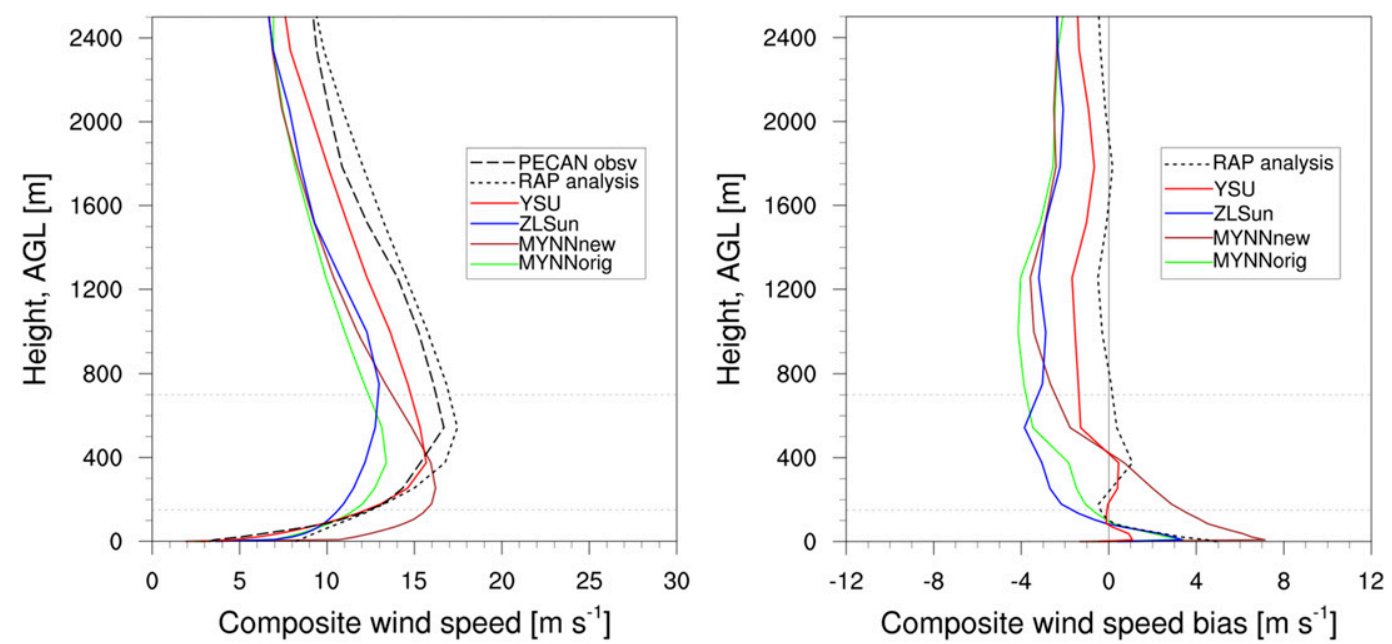

FIG. 4. For the same set of 60 experiments in Fig. 3, composites of WRF forecast and RAP analyses (left) wind speed vertical profile values and (right) bias relative to PECAN observations at 0600 UTC (18-h forecast). Light gray horizontal lines denote surface and LLJ layers as described in the text.

An explanation for the large differences in wind speeds at lower levels among the PBL schemes does not involve so much the surface-layer scheme, which is the same MYNN scheme that is invoked by MYNNorig, ZLSun, and MYNNnew, as it does the difference in mixing coefficients among the schemes. Stronger eddy diffusion coefficients for momentum $K_{m}$ (Fig. 5) and thus stronger mixing result in a reduction of wind speeds in and below the LLJ layer for ZLSun and MYNNorig as compared to the other PBL schemes. (Fig. 4). Conversely, smaller $K_{m}$ values for MYNNnew indicate relatively weak mixing and thus sustained stronger winds.

\section{b. Potential temperature forecasts}

MAEs for potential temperature forecasts in the LLJ layer for MYNNnew or YSU are of similar magnitude and are, respectively, $0.5 \mathrm{~K}(24 \%)$ and $0.4 \mathrm{~K}(19 \%)$ smaller than that of MYNNorig (Fig. 6). However, YSU results in a positive bias of $1.4 \mathrm{~K}$, which is larger in magnitude than the negative bias of MYNNorig. This warm bias by YSU is consistent with the results of previous studies (Cohen et al. 2015) and could be due to the entrainment of relatively warm air above the PBL (reference the potential temperature composite in Fig. 7) due to large-scale mixing of a nonlocal PBL scheme. The MYNNnew potential temperature forecast bias is nearly zero. Also, for the surface layer, MYNNnew is the only scheme that results in a reduction in MAE, which is $0.3^{\circ} \mathrm{C}$ $(17 \%)$ lower compared to MYNNorig, a result not found to be statistically significant. The RAP analysis exhibits MAE values less than $1 \mathrm{~K}$ and a bias of less than $0.5 \mathrm{~K}$ for all layers.
Consistent with these MAE values, a vertical profile of composite potential temperature forecast bias (Fig. 7) at 0600 UTC shows for YSU a relatively large warm bias between 1 and $2 \mathrm{~K}$ in the LLJ layer, and MYNNorig and ZLSun have a bias of $-1 \mathrm{~K}$ or cooler. The MYNNnew exhibits a bias of $1 \mathrm{~K}$ in the lower part of the LLJ layer. The RAP analysis maintains a bias of less than $0.25 \mathrm{~K}$ in the LLJ layer.

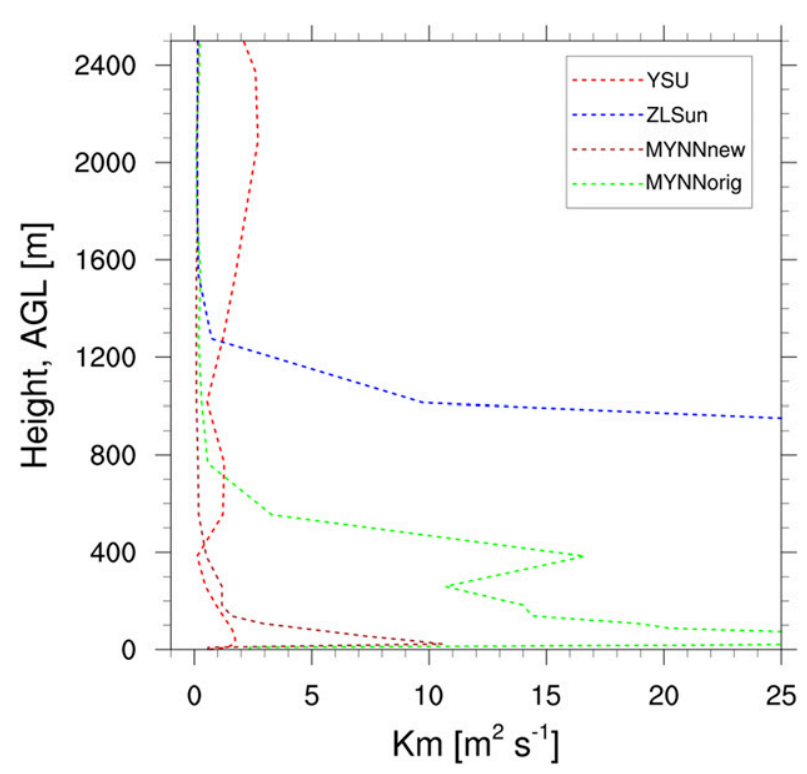

FIG. 5. Vertical profiles of eddy diffusion coefficients for momentum $K_{m}\left(\mathrm{~m}^{2} \mathrm{~s}^{-1}\right)$, from WRF forecasts with different PBL schemes (designated by color in the legend) for a single LLJ case at 0600 UTC 1 Jul 2015 at Hesston, KS. 

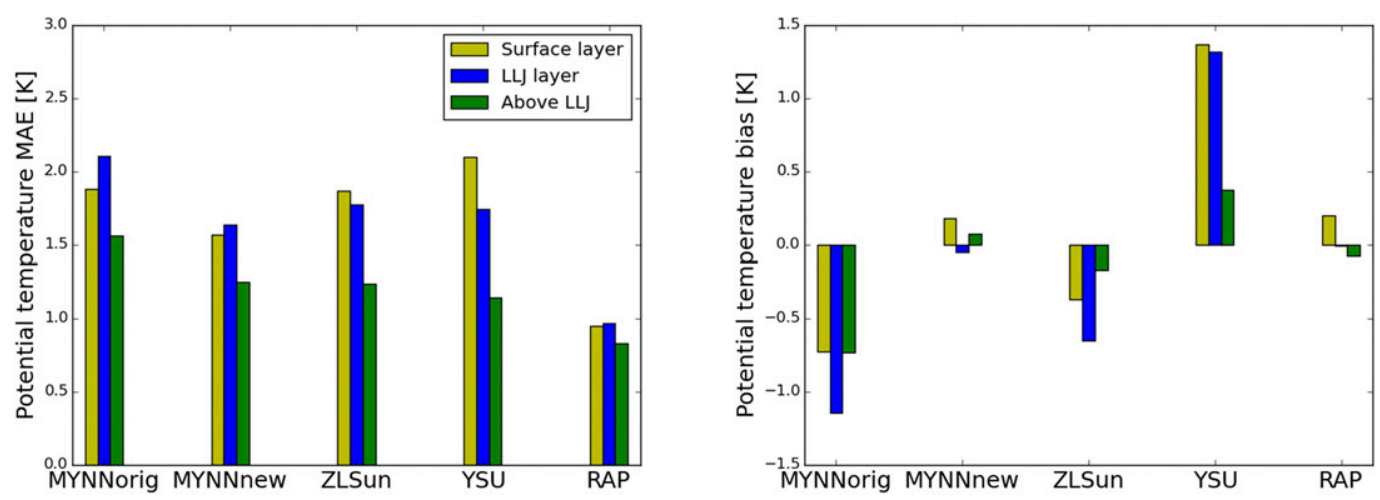

FIG. 6. As in Fig. 2, but for MAE and bias of WRF forecasts and RAP analyses of potential temperature (K).

In the surface layer, all PBL schemes as well as the RAP analysis demonstrate a warm bias. The YSU forecast bias of $2.0 \mathrm{~K}$ is double that of the other schemes. The warm biases for MYNNorig and ZLSun are depicted for 0600 UTC in Fig. 7, but these schemes produce cooler potential temperatures as compared to observations early on, thus resulting in negative bias values as calculated over the 6-h period (0000-0600 UTC) as in Fig. 6.

\section{c. Specific humidity forecasts}

MYNNnew and ZLSun both result in specific humidity forecast MAEs of $1.4 \mathrm{~g} \mathrm{~kg}^{-1}$ for the LLJ layer, which are $0.4 \mathrm{~g} \mathrm{~kg}^{-1}(22 \%)$ smaller than the specific humidity MAE for MYNNorig (Fig. 8). The MYNNnew forecast bias over the LLJ layer is smaller than that of the RAP analysis and nearly eliminated. YSU results in an MAE $0.3 \mathrm{~g} \mathrm{~kg}^{-1}(17 \%)$ higher than MYNNorig and a bias of $-1.8 \mathrm{~g} \mathrm{~kg}^{-1}$. The RAP analysis exhibits a dry bias of $0.5 \mathrm{~g} \mathrm{~kg}^{-1}$ and greater in the surface and LLJ layers.
A composite of specific humidity bias across all cases at 0600 UTC (Fig. 9) shows a distinct dry bias for YSU of $-1.25 \mathrm{~g} \mathrm{~kg}^{-1}$ in both the surface and LLJ layers. The large-scale mixing of a nonlocal PBL scheme could here as well allow for downward entrainment of relatively dry air. The lack of such large mixing with local PBL schemes results in a nearly equal moist bias for MYNNnew and an even larger bias for MYNNorig. A study analogous to the current one in the assessment of local and nonlocal PBL schemes over the Southeast United States (Cohen et al. 2017) does not give evidence of a strong YSU dry bias, which suggests possible regional differences in the application of a given PBL scheme.

The RAP analysis demonstrates a dry bias of $-1 \mathrm{~g} \mathrm{~kg}^{-1}$ in the surface layer, which is reduced to near zero toward the top of the LLJ layer. Above the LLJ layer at levels higher than $1800 \mathrm{~m}$, there is a dry bias for all PBL schemes. For the layer above the LLJ, there is not found a statistical significance in the MAE differences in specific
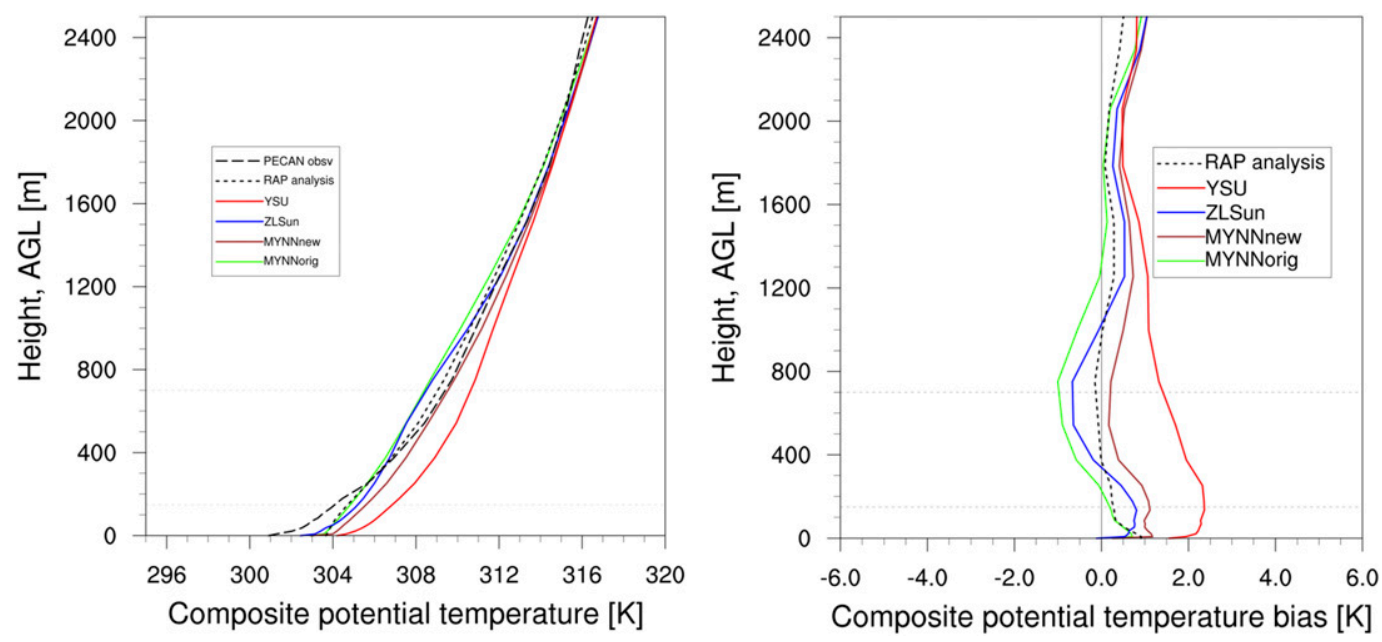

FIG. 7. As in Fig. 4, but showing vertical profiles of potential temperature and associated bias (K). 

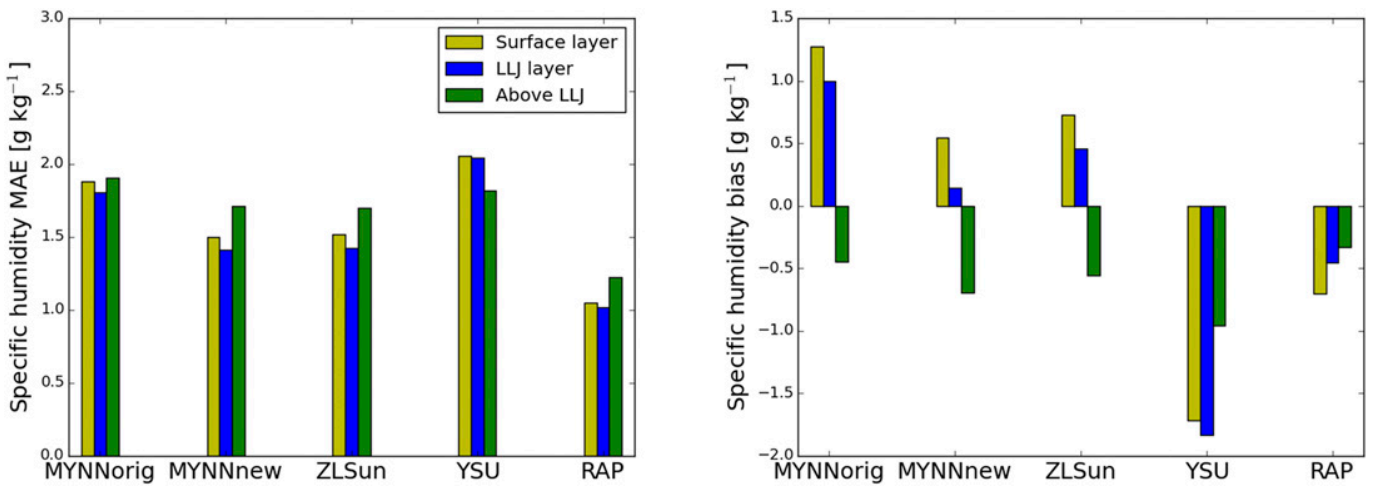

FIG. 8. As in Fig. 6, but for MAE and bias of WRF forecasts and RAP analyses for specific humidity $\left(\mathrm{g} \mathrm{kg}^{-1}\right)$.

humidity for MYNNnew, ZLSun, and YSU as compared to MYNNorig.

\section{d. MUCAPE and MUCIN forecasts}

Because the LLJ is known to play a critical role in the evolution and sustenance of nocturnal mesoscale convective systems that generally consist of at least some elevated convection, the most unstable CAPE (MUCAPE) is diagnosed for each forecast at each site and hour for which PECAN soundings are available. MUCAPE is determined by systematically calculating CAPE based on vertical profiles of temperature and dewpoint temperature for each case using lifted air parcels that initiate from different vertical grid levels at $25-\mathrm{hPa}$ increments between the surface and $700 \mathrm{hPa}$. Most unstable CIN (MUCIN) is calculated based on parcels that initiate from the same level as identified for the parcel having the MUCAPE. Forecast MAE and bias values for MUCAPE and MUCIN are then calculated relative to PECAN values and averaged across the experiment set in the same manner as per other variables.

YSU results in the lowest average MUCAPE MAE, with a value roughly half that of the other PBL schemes and with a near-zero bias (Fig. 10). The MUCAPE MAE for RAP is comparable to the result for YSU, although with a slight positive bias. A different trend was identified by Cohen et al. (2017) for cases from the Southeast, for which YSU slightly overpredicted CAPE and an observational analysis similar to RAP underpredicted MUCAPE.

The average MUCIN MAEs for all PBL schemes are similar, ranging between 105 and $120 \mathrm{~J} \mathrm{~kg}^{-1}$, with YSU being the largest. The relatively large MUCIN positive bias for YSU is associated with its slight warm bias (Fig. 6) and large dry bias (Fig. 8) at low levels, which results in a higher level of free convection and thus a stronger MUCIN. Likewise, a slight dry bias for RAP contributes to a positive MUCIN bias of nearly the same
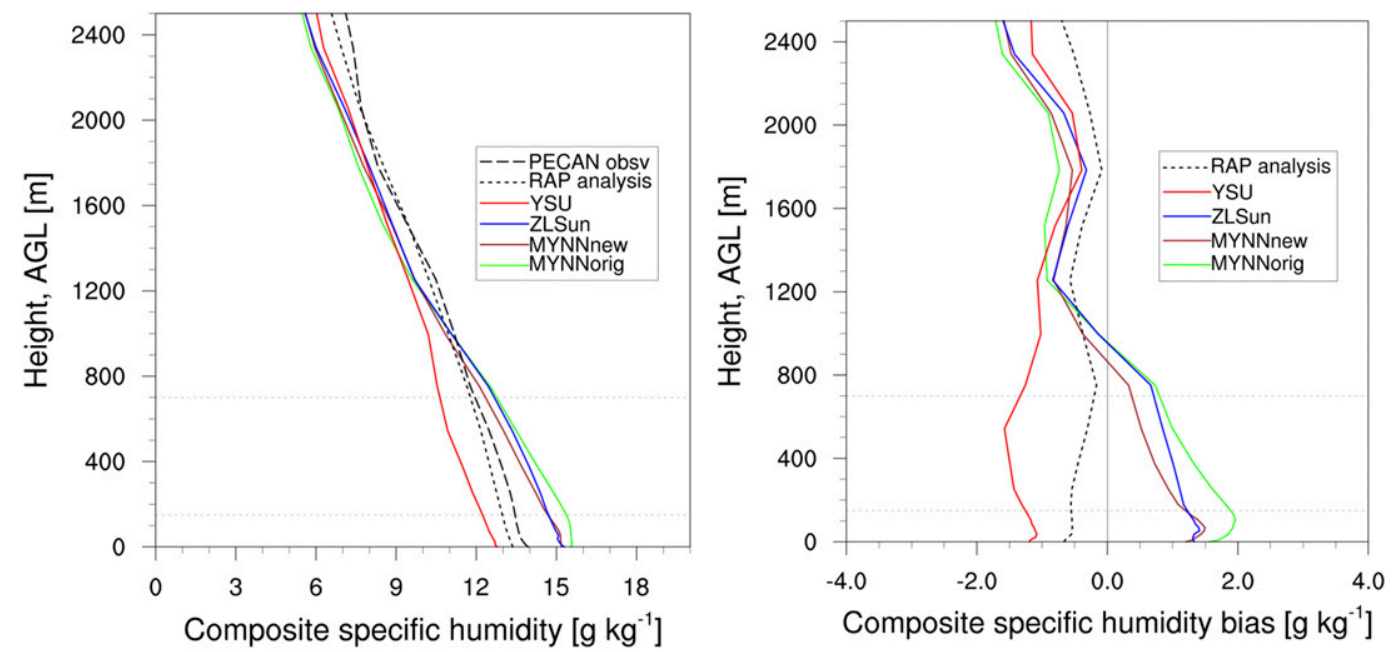

FIG. 9. As in Fig. 7, but showing vertical profiles of specific humidity and associated bias $\left(\mathrm{g} \mathrm{kg}^{-1}\right)$. 

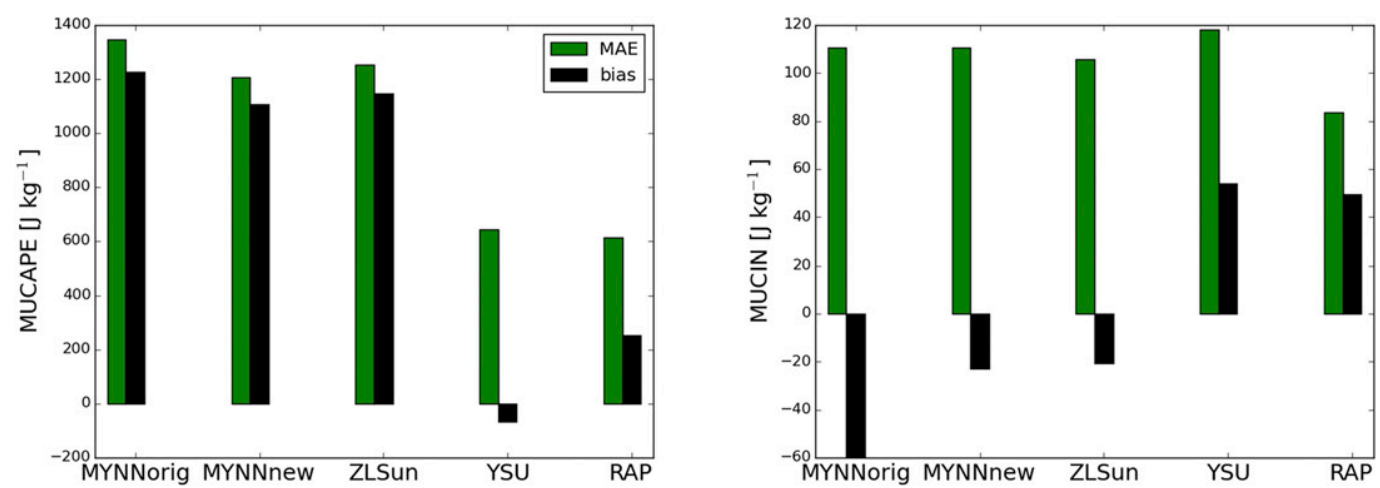

FIG. 10. WRF forecast (left) MUCAPE and (right) MUCIN MAE ( $\mathrm{J} \mathrm{kg}^{-1}$; green bars) and bias ( $\mathrm{J} \mathrm{kg}^{-1}$; black bars) by PBL scheme and for the RAP analysis. MUCAPE and MUCIN are diagnosed as given in the text.

magnitude as YSU. Conversely, the relatively large negative MUCIN bias for MYNNorig is likely associated with its relatively large moist bias (Fig. 8).

\section{Discussion and summary}

The performance of certain modifications to the MYNN PBL scheme in the WRF Model is evaluated using 12 LLJ cases for five sites (60 experiments) from the PECAN project for which extensive rawinsonde data are available. MYNNnew forecasts use a new set of closure parameters. The ZLSun forecasts use a PBL scheme that is modified to include TPE as well as a new mixing length. The MYNNnew and ZLSun forecasts are compared to MYNNorig and YSU forecasts, which use the original MYNN and YSU schemes, respectively. Additionally, the RAP analyses for the same experiments are evaluated against PECAN observations.

In the core LLJ region, YSU and MYNNnew result in the best wind speed forecasts with average MAEs across all 12 cases and five PECAN sites that are $22 \%$ and $19 \%$ lower, respectively, than MYNNorig, as well as the best potential temperature forecasts for both with respective MAEs 19\% and 24\% lower than MYNNorig. However, YSU has a warm potential temperature bias that is larger in magnitude than the cool 1.1-K bias of MYNNorig. YSU also results in a specific humidity dry bias and associated average MAE that is $17 \%$ above that for MYNNorig, while the other three MYNN schemes result in average specific humidity MAEs that are $22 \%$ smaller as compared to MYNNorig. It could be argued that MYNNnew performs the best overall in the LLJ layer with MAE values that are reduced by $19 \%$ or more as compared to MYNNorig in the forecast of wind speed, potential temperature, and specific humidity. Given the impact these variables have in determining local environmental instability, future work is needed to investigate explicitly the impact of PBL scheme modifications on convection initiation and evolution.

Below the LLJ and near the surface, the changes implemented in MYNNnew should be used with caution, as relatively high wind speed forecast errors occur with an average MAE $72 \%$ higher than that of MYNNorig. These errors are attributed to an LLJ maximum, the magnitude of which is well forecast by MYNNnew, but which is placed $300 \mathrm{~m}$ below that observed. Near the surface, ZLSun results in the smallest wind speed MAE, with a value $66 \%$ lower than MYNNorig. Thus, ZLSun would perform well for applications dependent on wind forecasts only in the lower levels of the boundary layer. Future work is warranted to identify PBL scheme modifications that would result in optimal performance at all levels.

Notable differences have been revealed between RAP analyses and the PECAN rawinsonde data. For the set of LLJ cases here, after the LLJ is fully developed RAP analyses exhibit an average wind speed bias of $0.5 \mathrm{~m} \mathrm{~s}^{-1}$ above the surface layer, but a relatively large average bias of $3 \mathrm{~m} \mathrm{~s}^{-1}$ in the lower surface layer, a result that should signal a need for caution when using RAP analyses for forecast verification of wind speeds near the surface. RAP analysis potential temperature and specific humidity biases are less severe, ranging between -1 and $1 \mathrm{~K}$ and between -1 and $0.5 \mathrm{~g} \mathrm{~kg}^{-1}$, respectively, over the surface and LLJ layers. Differences between RAP analyses and the PECAN soundings can vary significantly among different cases, such that care should be taken when validating model forecasts against model analyses for any one case. Future work should compare RAP analyses to observations for a larger sample of cases and compare the differences for LLJ cases with those valid for other types of events.

Acknowledgments. This work was supported by the National Science Foundation through Grant AGS1624947. 
The High Performance Computing Center at Iowa State University provided the computing resources for the WRF simulations. The PECAN rawinsonde data were made available through the Earth Observing Laboratory of the National Center for Atmospheric Research. The constructive comments of three anonymous reviewers helped to improve the paper.

\section{REFERENCES}

Augustine, J. A., and F. Caracena, 1994: Lower-tropospheric precursors to nocturnal MCS development over the central United States. Wea. Forecasting, 9, 116-135, https://doi.org/ 10.1175/1520-0434(1994)009<0116:LTPTNM > 2.0.CO;2.

Benjamin, S. G., and Coauthors, 2016: A North American hourly assimilation and model forecast cycle: The Rapid Refresh. Mon. Wea. Rev., 144, 1669-1694, https://doi.org/10.1175/ MWR-D-15-0242.1.

Chen, F., and J. Dudhia, 2001: Coupling an advanced land surfacehydrology model with the Penn State-NCAR MM5 modeling system. Part I: Model implementation and sensitivity. Mon. Wea. Rev., 129, 569-585, https://doi.org/10.1175/ 1520-0493(2001)129<0569:CAALSH > 2.0.CO;2.

Clark, R. 2016: FP3 Ellis, KS, radiosonde data, version 2.0 Earth Observing Laboratory, UCAR-NCAR, accessed 9 August 2016, https://doi.org/10.5065/D6GM85DZ.

Cohen, A. E., S. M. Cavallo, M. C. Coniglio, and H. E. Brooks, 2015: A review of planetary boundary layer parameterization schemes and their sensitivity in simulating southeastern U.S. cold season severe weather environments. Wea. Forecasting, 30, 591-612, https://doi.org/10.1175/WAF-D-14-00105.1.

$\longrightarrow,-,-,-$, and I. L. Jirak, 2017: Evaluation of multiple planetary boundary layer parameterization schemes in southeast U.S. cold season severe thunderstorm environments. Wea. Forecasting, 32, 1857-1884, https://doi.org/10.1175/ WAF-D-16-0193.1.

Dudhia, J., 1989: Numerical study of convection observed during the Winter Monsoon Experiment using a mesoscale twodimensional model. J. Atmos. Sci., 46, 3077-3107, https://doi.org/ 10.1175/1520-0469(1989)046<3077:NSOCOD>2.0.CO;2.

Geerts, B., and Coauthors, 2017: The 2015 Plains Elevated Convection at Night Field Project. Bull. Amer. Meteor. Soc., 98 , 767-786, https://doi.org/10.1175/BAMS-D-15-00257.1.

Ghasemi, A., and S. Zahediasl, 2012: Normality tests for statistical analysis: A guide for non-statisticians. Int. J. Endocrinol. Metab., 10, 486-489, https://doi.org/10.5812/ijem.3505.

Grachev, A. A., E. L Andreas, C. W. Fairall, P. S. Guest, and P. O. G. Persson, 2013: The critical Richardson number and limits of applicability of local similarity theory in the stable boundary layer. Bound.-Layer Meteor., 147, 51-82, https://doi.org/ 10.1007/s10546-012-9771-0.

Higgins, R. W., Y. Yao, E. S. Yarosh, J. E. Janowiak, and K. C. Mo, 1997: Influence of the Great Plains low-level jet on summertime precipitation and moisture transport over the central United States. J. Climate, 10, 481-507, https://doi.org/10.1175/ 1520-0442(1997)010<0481:IOTGPL > 2.0.CO;2.

Holdridge, D., and D. Turner, 2015: FP6 Hesston, KS, radiosonde data, version 1.0. Earth Observing Laboratory, UCAR/NCAR, accessed 9 August 2016, https://doi.org/10.5065/D6765CD0.

Hong, S.-Y., J. Dudhia, and S.-H. Chen, 2004: A revised approach to ice microphysical processes for the bulk parameterization of clouds and precipitation. Mon. Wea. Rev., 132, 103-120, https:// doi.org/10.1175/1520-0493(2004)132<0103:ARATIM>2.0.CO;2.

—, Y. Noh, and J. Dudhia, 2006: A new vertical diffusion package with an explicit treatment of entrainment processes. Mon. Wea. Rev., 134, 2318-2341, https://doi.org/10.1175/MWR3199.1.

Hu, X.-M., J. W. Nielsen-Gammon, and F. Zhang, 2010: Evaluation of three planetary boundary layer schemes in the WRF Model. J. Appl. Meteor. Climatol., 49, 1831-1843, https://doi.org/10.1175/ 2010JAMC2432.1.

_ P. M. Klein, and M. Xue, 2013: Evaluation of the updated YSU planetary boundary layer scheme within WRF for wind resource and air quality assessments. J. Geophys. Res. Atmos., 118, 10 490-10 505, https://doi.org/10.1002/jgrd.50823.

Jahn, D. E., E. S. Takle, and W. A. Gallus Jr., 2017a: Improving wind-ramp forecasts in the stable boundary layer. Bound.Layer Meteor., 163, 423-446, https://doi.org/10.1007/s10546017-0237-2.

- $\longrightarrow$, and $\longrightarrow, 2017 \mathrm{~b}$ : Wind-ramp-forecast sensitivity to boundary-layer scheme closure parameters. Bound.-Layer Meteor., 164, 475-490, https://doi.org/10.1007/s10546-017-0250-5.

Kleczek, M. A., G.-J. Steeneveld, and A. A. M. Holtslag, 2014: Evaluation of the Weather Research and Forecast mesoscale model for GABLS3: Impact of boundary-layer schemes, boundary conditions and spin-up. Bound.-Layer Meteor., 152, 213-243, https://doi.org/10.1007/s10546-014-9925-3.

Klein, P. M., X.-M. Hu, A. Shapiro, and M. Xue, 2016: Linkages between boundary-layer structure and the development of nocturnal low-level jets in central Oklahoma. Bound.-Layer Meteor., 158, 383-408, https://doi.org/10.1007/s10546-015-0097-6.

Mellor, G. L., and T. Yamada, 1982: Development of a turbulence closure model for geophysical fluid problems. Rev. Geophys. Space Phys., 20, 851-875, https://doi.org/10.1029/RG020i004p00851.

Milovac, J., K. Warrach-Sagi, A. Behrendt, F. Späth, J. Ingwersen, and V. Wulfmeyer, 2016: Investigation of PBL schemes combining the WRF model simulations with scanning water vapor differential absorption lidar measurements. J. Geophys. Res. Atmos., 121, 624-649, https://doi.org/10.1002/2015JD023927.

Mlawer, E. J., S. J. Taubman, P. D. Brown, M. J. Iacono, and S. A. Clough, 1997: Radiative transfer for inhomogeneous atmospheres: RRTM, a validated correlated model for the longwave. J. Geophys. Res., 102, 16663-16682, https://doi.org/ 10.1029/97JD00237.

Nakanishi, M., 2001: Improvement of the Mellor-Yamada turbulence closure model based on large-eddy simulation data. Bound.-Layer Meteor., 99, 349-378, https://doi.org/10.1023/A: 1018915827400.

— model with condensation physics: Its design and verification. Bound.-Layer Meteor., 112, 1-31, https://doi.org/10.1023/B: BOUN.0000020164.04146.98.

Schmengler, M., F. D. Costa, O. C. Acevedo, F. S. Puhales, G. Demarco, L. G. N. Martins, and L. E. Medeiros, 2015: Comparison of mixing length formulations in a single-column model simulation for a very stable site. Amer. J. Environ. Eng., 5, 106-118, https://doi.org/10.5923/s.ajee.201501.14.

Skamarock, W. C., and Coauthors, 2008: A description of the Advanced Research WRF version 3. NCAR Tech. Note NCAR/ TN-475+STR, 113 pp., http://dx.doi.org/10.5065/D68S4MVH.

Squitieri, B. J., and W. A. Gallus Jr., 2016: WRF forecasts of Great Plains nocturnal low-level jet-driven MCSs. Part I: Correlation between low-level jet forecast accuracy and MCS precipitation forecast skill. Wea. Forecasting, 31, 1301-1323, https://doi.org/ 10.1175/WAF-D-15-0151.1. 
Stensrud, D. J., 1996: Importance of low-level jets to climate: A review. J. Climate, 9, 1698-1711, https://doi.org/10.1175/15200442(1996)009<1698:IOLLJT>2.0.CO;2.

Sun, J., L. Mahrt, R. M. Banta, and Y. L. Pichugina, 2012: Turbulence regimes and turbulence intermittency in the stable boundary layer during CASES-99. J. Atmos. Sci., 69, 338-351, https://doi.org/10.1175/JAS-D-11-082.1.

Thompson, R. L., R. Edwards, J. A. Hart, K. L. Elmore, and P. Markowski, 2003: Close proximity soundings within supercell environments obtained from the Rapid Update Cycle. Wea. Forecasting, 18, 1243-1261, https://doi.org/10.1175/15200434(2003)018<1243:CPSWSE > 2.0.CO;2.

UCAR-NCAR, 2016a: FP4 NCAR/EOL QC soundings, version 2.0. Earth Observing Laboratory, UCAR-NCAR, accessed 9 August 2016, https://doi.org/10.5065/D63776XH.

, 2016b: FP5 NCAR/EOL soundings, version 2.0. Earth Observing Laboratory, UCAR-NCAR, accessed 9 August 2016, https:// doi.org/10.5065/D6ZG6QF7.
Vermeesch, K. 2015: FP2 Greensburg, KS, radiosonde data, version 1.0. Earth Observing Laboratory, accessed 9 August 2016, UCAR/NCAR, https://doi.org/10.5065/ D6FQ9TPH.

Walters, C. K., and J. A. Winkler, 2001: Airflow configurations of warm season southerly low-level wind maxima in the Great Plains. Part II: The synoptic and subsynoptic-scale environment. Wea. Forecasting, 16, 531-551, https://doi.org/10.1175/ 1520-0434(2001)016<0531:ACOWSS >2.0.CO;2.

Wang, S. Y., and T. C. Chen, 2009: The late-spring maximum of rainfall over the U.S. central plains and the role of the lowlevel jet. J. Climate, 22, 4696-4709, https://doi.org/10.1175/ 2009JCLI2719.1.

Zilitinkevich, S. S., T. Elperin, N. Kleeorin, and I. Rogachevskii, 2007: Energy- and flux-budget (EFB) turbulence closure model for stably stratified flows. Part I: Steady-state, homogeneous regimes. Bound.-Layer Meteor., 125, 167-191, https:// doi.org/10.1007/s10546-007-9189-2. 